\title{
State-of-the-art ultrasonic sensor designed to improve longwall production rates and operation safety
}

\author{
Slawomir BARTOSZEK ${ }^{1 *}$, Sebastian JENDRYSIK ${ }^{2}$, Joanna ROGALA-ROJEK $^{3}$, \\ Mariusz WOSZCZYŃSKI ${ }^{4}$, Krzysztof KRAUZE ${ }^{5}$ and Jaroslaw JOOSTBERENS ${ }^{6}$
}

\author{
Authors' affiliations and addresses: \\ ${ }^{1}$ KOMAG Institute of Mining Technology, Department \\ of Mechatronics Systems, \\ Pszczyńska 37, 44-101 Gliwice, Poland \\ e-mail: sbartoszek@komag.eu \\ ${ }^{2}$ KOMAG Institute of Mining Technology, Department \\ of Mechatronics Systems, \\ Pszczyńska 37, 44-101 Gliwice, Poland \\ e-mail: sjendrysik@komag.eu \\ ${ }^{3}$ KOMAG Institute of Mining Technology, Department \\ of Mechatronics Systems, \\ Pszczyńska 37, 44-101 Gliwice, Poland \\ e-mail: jrogala@komag.eu \\ ${ }^{4}$ KOMAG Institute of Mining Technology, Department \\ of Mechatronics Systems, \\ Pszczyńska 37, 44-101 Gliwice, Poland \\ e-mail: mwoszczynski@komag.eu
}

${ }^{5}$ Faculty of Mechanical Engineering and Robotics, AGH University of Science and Technology, Mickiewicza 30, Kraków, Poland

e-mail: krauze@agh.edu.pl

${ }^{6}$ Silesian University of Technology, Department of Electrical Engineering and Industrial Automation, Faculty of Mining, Safety Engineering and Industrial Automation, Akademicka 2, 44-100 Gliwice, Poland e-mail: Jaroslaw.Joostberens@ @olsl.pl

\section{*Correspondence:}

Sławomir Bartoszek, KOMAG Institute of Mining Technology, Department of Mechatronics Systems, Pszczyńska 37, 44-101 Gliwice, Poland

tel: +4832237453

e-mail: sbartoszek@komag.eu

Funding information:

Research Fund for Coal and Steel (RFCS)

Grant 752504

\section{Acknowledgement:}

The research work undertaken in PRASS III (Productivity and safety of shield support), grant 752504 (2017) was supported by EU Research Fund for Coal and Steel (RFCS) as well as the Ministry of Science and Higher Education.

\section{How to cite this article:}

Bartoszek, S., Jendrysik, S., Rogala-Rojek, J., Woszczyński, M., Krauze, K. and Joostberens, J. (2021). State-of-the-art ultrasonic sensor designed to improve longwall production rates and operation safety. Acta Montanistica Slovaca. Volume 26 (1) 149-160

DOI:

https://doi.org/10.46544/AMS.v26i1.13

\begin{abstract}
The article describes issues related to the development of a sensor measuring the distance from the end of the shield support canopy to the face of the longwall panel. The sensor's task is to detect rock falls because in such a case, empty spaces in the coal seam below the roof are generated. The sensor is a part of the system which task is to predict unfavourable behaviour of the longwall roof affecting the continuity of mining. Due to an untypical workplace and difficult conditions prevailing there, it was not possible to use a typical sensor. The ultrasonic technique was used for this purpose. The next research stages related to the development of the sensor were described. Tests of various types of ultrasonic transducers, working at different parameters, were described. Only transducers with a closed structure were considered because they can operate in the presence of high dustiness and humidity. The sensor casing was adapted to a specific type of shield support. The installation location should not be accidental, as an additional hinged shield is mounted at the end of the canopy, which is an obstacle in the measuring track and can even completely cover it, making measurements impossible. The sensor is mounted close to the side edge of the shield support canopy using small free space, enabling a measurement. Structural elements of the canopy are obstacles in the measuring track and are a source of interference of the received signals. The ultrasonic transducers are built-in tubes, which direct the ultrasonic wave and amplify the received signals. The results of laboratory tests of the model of the path measurement sensor are presented. They describe the impact of analysed aspects, i.e. the type of transducers used, the structure of the surface that the wave is reflected from and the mechanical solutions on the quality of received signals. A prototype of a sensor installed on shield support is presented.
\end{abstract}

\section{Keywords}

Longwall panel, shield support, monitoring system, distance sensor, ultrasounds 


\section{Introduction}

In longwall mining systems, proper roof support, provided by powered roof support sections, determines the continuity and effectiveness of mining operations. The proper support of the roof protects the working machinery from damage and ensures the safety of the personnel working in the area. In order to ensure correct interaction of roof support with the rock mass, it must be selected for a particular face, taking into account not only the height of the seam but also the geological and technical conditions (Szurgacz and Brodny, 2020). Various types of numerical methods are used for this purpose, helping to simulate the interaction of different types of longwall support with the rock mass (Islavath et al., 2016; Verma and Deb, 2006; Prusek et al., 2016).

Studies and analyses prove that poor working parameters of powered roof support sections and their bad geometry in the long term cause loss of roof stability, which consequently leads to rockfall (Płonka and Rajwa, 2018; Płonka et al., 2017; Prusek and Masny, 2015; Rajwa, 2016; Rajwa et al., 2017). Uncontrolled rockfall occurs in the uncovered area between the end of the canopy of the powered roof support and the face of the longwall, causing backfilling of the conveyor, which causing interruptions in mining and putting the workers in the area at risk (Langosch and Volker, 2003; Chen et al., 2017; Andras et al., 2017; Rajwa et al. 2020). Cracks in the main roof of the longwall in unpredictable places cause a sudden increase in the pressure induced by the roof, may in extreme situations cause damage to the powered roof support, which consequently threatens the collapse of the longwall (Wen et al., 2005; Le, 2021). In a publication (Rajwa et al., 2020), it has been proven that a proper geometry of the longwall support during mining operations, when the pressure induced by the roof is distributed over the entire canopy area, significantly reduces the cracking zone in the roof rock of the longwall.

One of the most important factors in providing stable operation of a longwall system is to keep the distance between the end of the canopy and the face of the longwall as short as possible. In particular, after the shearer passes through before the support is moved towards the face of the longwall, the unsupported area of the roof increases, and if this situation continues for a long period of time, it may also be the cause of a part of the roof breaking off. (Haijun et al., 2016; Frith, 2013; Rajwa, 2020). In the cases described above, voids are formed between the end of the canopy and the face of the wall, and their detection can be an indicator of the condition of the roof and thus also of the quality of the wall guidance.

The introduction of monitoring systems and sensors operating wirelessly in the mine, often forming underground multi-node communication networks, has brought new opportunities in terms of recording and controlling powered roof support parameters. Connecting the mine's underground with the infrastructure located on the surface, as well as with the global Internet, has made it possible to observe the condition of the roof support in real-time. Monitoring the performance of powered roof support opens up new possibilities in terms of prediction and early warning of potential roof collapse hazards so that negative phenomena can be addressed and prevented earlier (Cheng et al., 2020; Rajwa et al., 2019). Currently, the source of information in these types of systems is the monitoring of the working pressure in the legs of the longwall support using battery-powered sensors. (Wang et al. 2018; Jingyi Cheng et al., 2018; Cheng et al., 2020; Rajwa et al., 2019; Szurgacz and Brodny 2019; Szurgacz et al., 2020). For the prediction of negative phenomena occurring in the roof, the information on the geometry of individual parts of the support through measurements with inclinometers is important (Witek and Prusek, 2016; Kalentev et al., 2017).

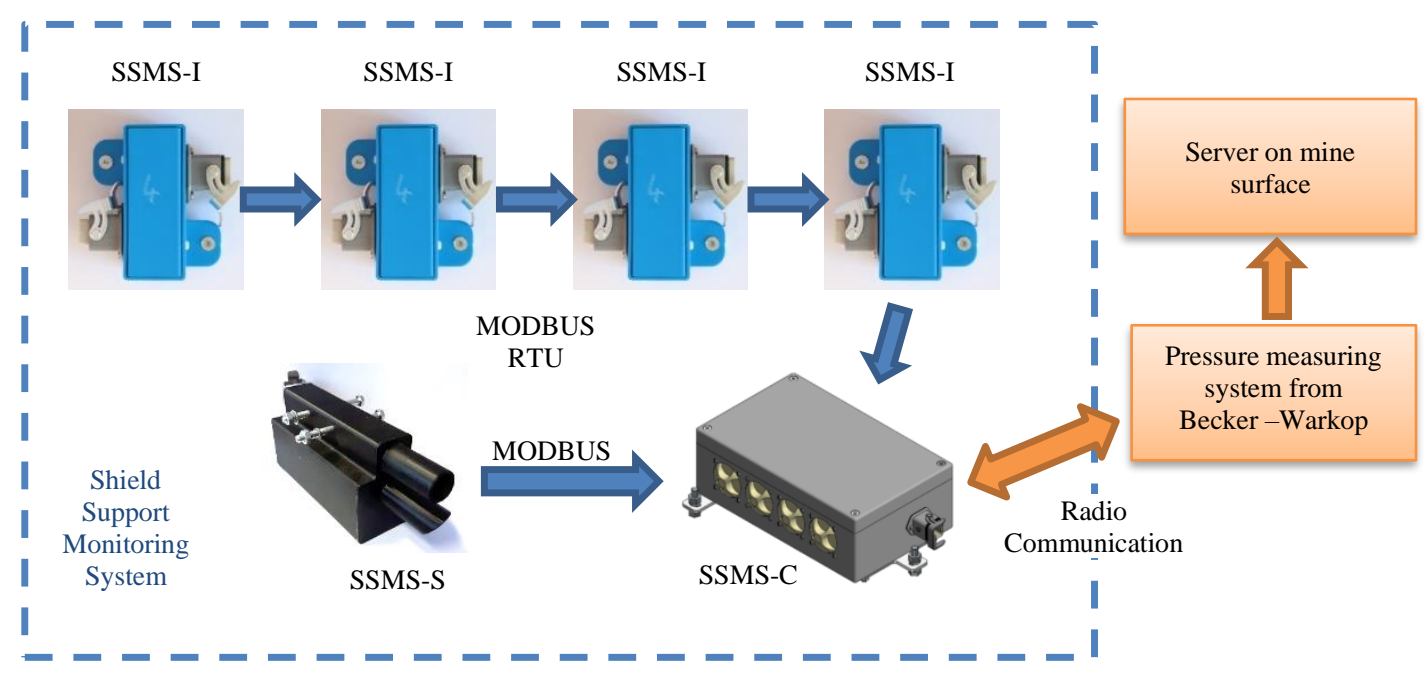

Fig. 1 Shield Support Monitoring System structure

In 2017, the international consortium, with the participation of the KOMAG Institute of Mining Technology, commenced implementation of the project co-financed by the European Coal and Steel Fund (RFCS), called 
PRASS III (Productivity and safety of shield support). Its aim is to develop a system that will enable detection and prediction of threats related to rock falls in a longwall panel on the basis of monitoring the parameters of shield supports operation (Jasiulek, 2019). The hardware part of the system installed on the shield support, which realises the measurement of the geometry, is called Shield Support Monitoring System (Jasiulek et al., 2019). The structure of the system is shown in Fig. 1. The task of the system is to measure the inclination angles of individual parts of the shield support and to measure the distance between the shield support and the longwall (Fig. 2).

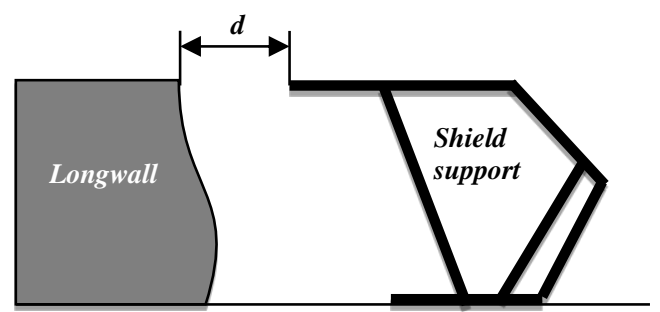

Fig. 2. Tip to face distance

The sensors are connected to the central unit SSMS-C, which is connected wirelessly to the pressure measurement system in hydraulic legs. The measurement data are sent to the server located on the mine surface. The behaviour of the working roof is analysed there.

The article describes the issues related to the development of the sensor that realises the mentioned distance measurement. The sensor's task is to detect rock falls because in such a case, empty spaces in the coal seam below the roof are generated. The untypical installation location of the sensor and the requirements of the ATEX 2014/34/EU Directive made it necessary to develop a dedicated sensor adapted to the prevailing conditions in the working. As the shield support follows the advance of the longwall, the maximum operating range of the sensor is assumed to be $5 \mathrm{~m}$. Under normal operating conditions, the support is practically pushed to the face of the longwall, and the distance increases only after the longwall shearer is passed by the thickness of the cutting drum.

\section{Material and Methods}

The described sensor is to measure a distance between the end of the shield support and the face of the longwall. Taking into account the difficult conditions prevailing in a longwall panel, the sensor uses ultrasonic technology. Ultrasound is well suited for measuring distances up to several meters, and its range of application is closely related to the frequency of generated waves (Biryukova and Koretskaya, 2020; Janu and Sramek, 2020; Zhmud et al., 2018; Bartoszek and Kost, 2018; Xu et al., 2017). A measuring method, which consists of measuring the propagation time (ToF) (Zafari et al., 2019; Plets et al., 2019) of waves reflected from the longwall surface, i.e. measurement of the echo (Fig. 3), was applied.

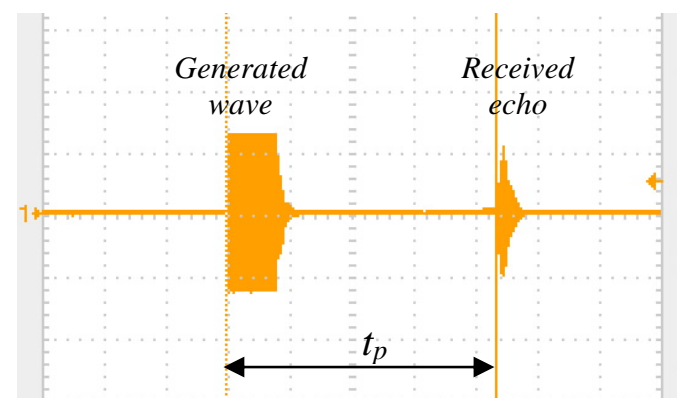

Fig. 3. Distance measurement based on wave propagation time measurement

The distance is determined using the following formula (Eq. 1):

$$
d=v_{U S} \cdot \frac{t_{p}}{2}
$$

where: $t_{p}$ - the time between the wave sent and received echo, $v_{U S}$ - speed of ultrasonic wave propagation. The speed of ultrasonic wave propagation in the air is determined according to the relationship (Eq. 2) (Gudra, 2005). 


$$
v_{U S}=\sqrt{\frac{\kappa(T) p_{0} T}{\rho_{0} T_{293}}}
$$

where:

$\rho_{0}$ - gas density under normal conditions, $p_{0}$ - gas pressure under normal conditions, $T$ - gas temperature, $T_{293}=293 \mathrm{~K}, \kappa(\mathrm{T})-$ dimensionless adiabate exponent equal to $c_{p} / c_{v}, c_{p}-$ specific heat at constant pressure, $c_{v}$ - specific heat at constant volume.

According to formula (Eq. 2) and information in the literature (Slusariuc et al., 2018; Kim et al., 2019), the medium temperature has the greatest impact on the speed of wave propagation. The system will be equipped with a temperature measurement function. In the calculation procedures used, the speed of ultrasonic wave propagation is expressed by formula (Eq. 3) (Gudra, 2005):

$$
v_{U S}=331.85(1+0.00183 T)
$$

The ultrasonic wave attenuation coefficient in the gaseous medium can be described by the following formula (Gudra, 2005):

$$
\zeta=\frac{2 \pi^{2} f^{2}}{p} \sqrt{\frac{\rho_{0} T_{0}}{\kappa(T)^{3} p_{0}}\left[\frac{4}{3} \eta(T)+\sigma(T) \frac{\kappa(T)-1}{c_{p}(T, p)}\right]}
$$

where: $f$ - wave frequency, $p$ - gas pressure, $\rho_{0}$ - gas density under normal conditions, $p_{0}$ - gas pressure under normal conditions, $T$ - gas temperature, $\eta$-dynamic viscosity index, $\sigma(\mathrm{T})$ - thermal conductivity coefficient, $\kappa(\mathrm{T})$ - dimensionless adiabate exponent equal to $c_{p} / c_{v}, c_{p}$ - specific heat at constant pressure, $c_{v}-$ specific heat at constant volume.

Assuming small changes in atmospheric pressure, formula (Eq. 1) can be presented in a simplified form (Gudra, 2005):

$$
\zeta=\frac{f^{2} k(T)}{p}
$$

where: $k(\mathrm{~T})$ - constant for a specific temperature, $p$ - gas pressure, $f$ - wave frequency. On the basis of the presented relationships (Eq. 4) and (Eq. 5), it can be clearly stated that the frequency of the generated signal has the greatest impact on the wave attenuation in the gaseous medium.

The selection of proper components for the generation and reception of ultrasonic waves was an important task. Several types of ultrasonic transducers (Fig. 4) differing in their operational parameters were tested (Tab. 1).

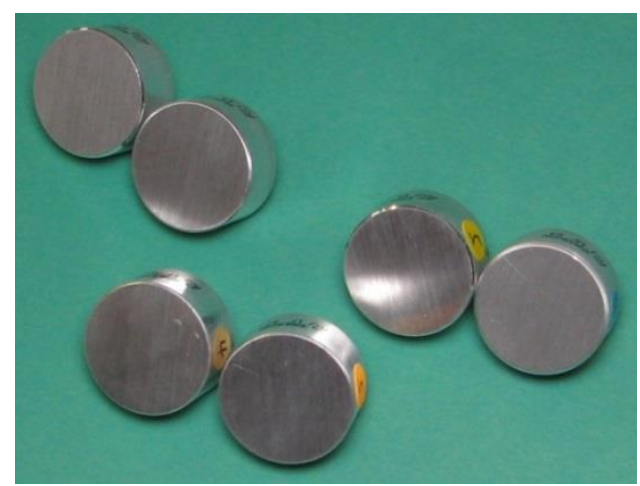

Fig. 4. Selected ultrasonic transducers

The choice of ultrasonic transducers was limited by several criteria related to the place of operation of the sensor. The sensor will be installed at the end of the shield support canopy. It is a place exposed to damage due to close contact with operating longwall shearer cutting a coal deposit. The sensor should be resistant to damage, for example, from ejected rocks during the mining process. However, its dimensions should not be too large and should not stand out too far from the roof of the longwall shearer's casing as it could be hit by the shearer's cutting body. Therefore, the dimensions of the transducers should not be too large. Transducers with a diameter of $25 \mathrm{~mm}$ were selected. Such a size of sensors ensures the assumed measuring range of several meters. 
Tab. 1. Parameters of selected ultrasonic transducers

\begin{tabular}{|c|c|c|c|c|}
\hline Parameter & Transducer No.1 & Transducer No.2 & Transducer No.3 & Transducer No.4 \\
\hline Center Frequency & $25 \mathrm{kHz}$ & $32,8 \mathrm{kHz}$ & $40 \mathrm{kHz}$ & $40 \mathrm{kHz}$ \\
\hline $\begin{array}{c}\text { Transmitting Sound Pressure } \\
\text { Level }(0 \mathrm{~dB} \text { re } 0.0002 \mu \text { bar per } \\
10 \mathrm{Vrms} \text { at } 30 \mathrm{~cm})\end{array}$ & $113 \mathrm{~dB}$ & $113 \mathrm{~dB}$ & $115 \mathrm{~dB}$ & $110 \mathrm{~dB}$ \\
\hline $\begin{array}{l}\text { Receiving Sensitivity } \\
\quad \text { (re } 1 \text { volt/ } \mu \text { bar) }\end{array}$ & $-63 \mathrm{~dB}$ & $-67 \mathrm{~dB}$ & $-70 \mathrm{~dB}$ & $-72 \mathrm{~dB}$ \\
\hline Transducers type & $\begin{array}{l}\text { Transmitter } \\
\text { and receiver }\end{array}$ & $\begin{array}{l}\text { Transmitter } \\
\text { and receiver }\end{array}$ & $\begin{array}{l}\text { Transmitter } \\
\text { and receiver }\end{array}$ & Transceiver \\
\hline Diameter & $25 \mathrm{~mm}$ & $25 \mathrm{~mm}$ & $25 \mathrm{~mm}$ & $25 \mathrm{~mm}$ \\
\hline
\end{tabular}

The use of larger-size sensors would not be justified, also due to the higher power needed to generate a wave. Due to the possibility of operation in potentially explosive atmospheres due to the presence of methane and coal dust, the sensor must have an intrinsically safe design, in accordance with the ATEX directive, and such a design results in maximum power limitations. Importantly, the sensor is powered by a built-in battery, so it must be as energyefficient as possible, as it should work without the necessity of replacing the battery for at least 1 year. The characteristic feature of the selected sensors is their closed structure, which makes them resistant to harsh environmental conditions prevailing in the longwall panels. The selected ultrasonic transducers vary in frequency. Two types of selected transmitters work in a transmitter-receiver configuration. One type works as a transceiver, i.e. one component, which is used both to generate and receive ultrasonic waves.

The ultrasonic transducer test stand is presented in Fig. 5.

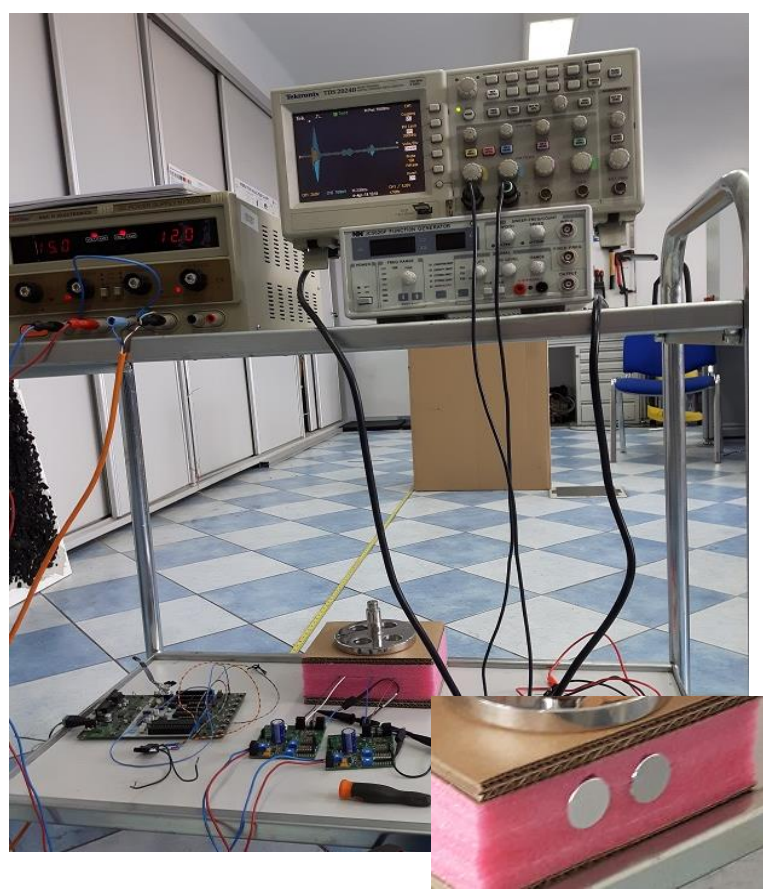

Fig. 5. Test stand for measuring the parameters of transmitted signals

Tab. 2. Voltage of the transmitters supply signal

\begin{tabular}{c|c}
\hline Transducers type & $\begin{array}{c}\text { Driving voltage } \\
{\left[\mathrm{V}_{\mathrm{rms}}\right]}\end{array}$ \\
\hline 1 & 15 \\
2 & 20 \\
3 & 20 \\
4 & 50 \\
\hline
\end{tabular}


The ultrasonic waves were reflected from a moving object at a maximum distance of $5 \mathrm{~m}$. A frequency-controlled generator was used in the tests, which was each time adjusted to the resonance frequency of the tested type of ultrasonic transducers. The generator was connected through the prepared microcontroller control system, enabling cyclic sending of the signal to the transmitter in the form of an impulse of duration $2 \mathrm{~ms}$. Tab. 2 lists the voltage of the signal used to drive the transducers during testing. The receiving transducer is connected to a prepared system enabling amplification and bandpass filtering of the received signal. The signal was recorded using a digital oscilloscope.

\section{Results and Discussion}

The graph in Fig. 6 presents the signal level recorded by selected ultrasonic transducers described in Tab. 1

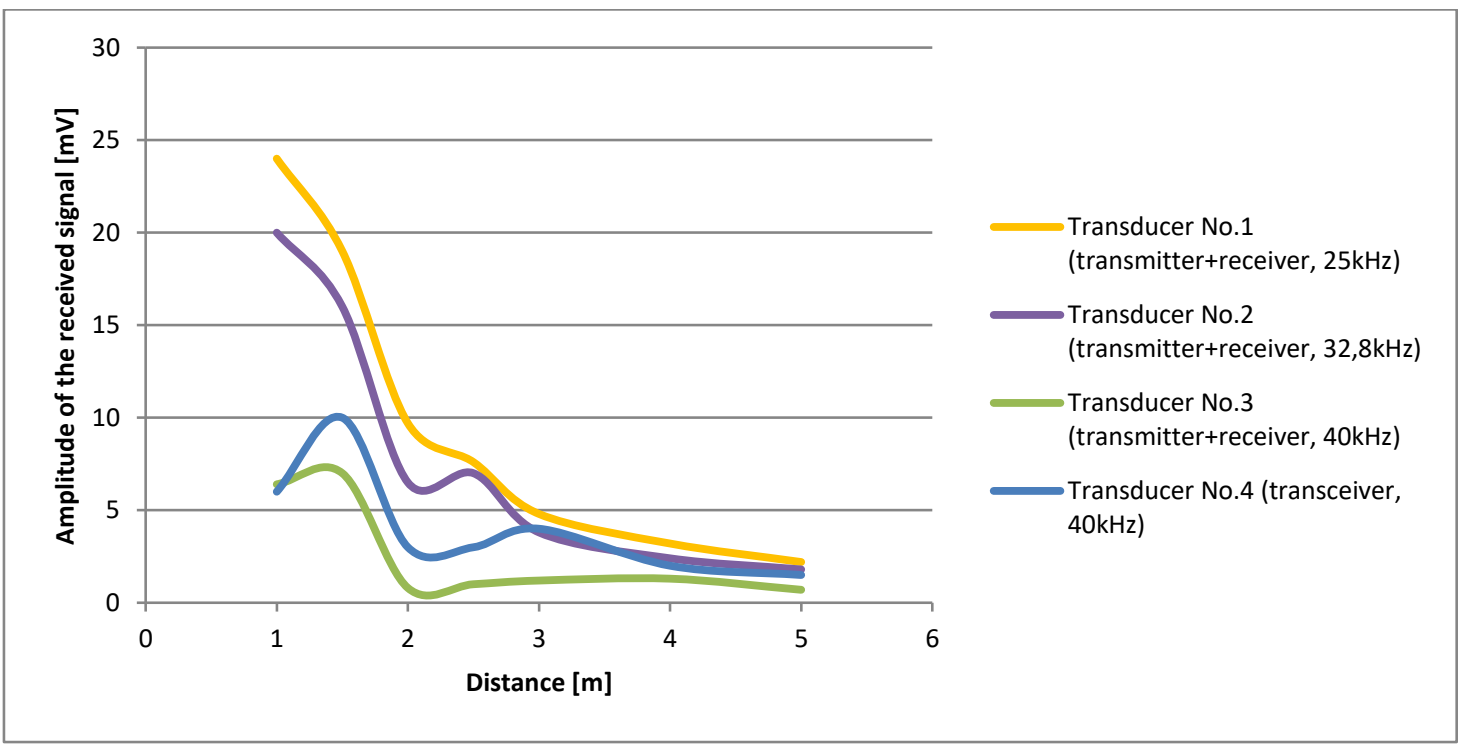

Fig. 6. The amplitude of signals recorded by the transducers from Table 1

According to Eq. 5, the frequency of ultrasonic waves has a significant impact on their damping rate during propagation in the air and thus on the measuring range of the system. This is confirmed by the results of the tests. The highest amplitude was recorded using transducers with the lowest frequency $25 \mathrm{kHz}$. The lowest signal amplitudes were recorded in the case of transducers of $40 \mathrm{kHz}$ frequency. It was observed both in the case of transmitter-receiver pairs, as well as in the case of a transceiver, which was even given a higher amplitude trigger signal. On this basis, we can conclude that the transmitters with the lowest possible frequency should be used. However, the use of a lower frequency also has disadvantages. The lower frequency means a longer wavelength, and therefore it takes more time to give a trigger signal with the same number of periods. This increases the sensor's blind spot, i.e. the minimum limit of its correct functioning. In this area, the trigger signal and interference from the transmitter overlaps the echo signal, i.e. the signal reflected from an obstacle in close proximity. This signal is not detected by the receiving system. In the sensor described above, it was decided to use an indirect solution, i.e. $32.8 \mathrm{kHz}$ transmitters were selected. As shown in Figure 6, the amplitude of the signal received with this transducer was much higher than with $40 \mathrm{kHz}$ transducers. The highest possible amplitude of the recorded signals was taken into account due to the unknown structure of the longwall face, which would undoubtedly affect signal attenuation. During the tests, a smooth surface was used from which ultrasonic waves were reflected; this surface was set at an angle close to a right angle in relation to the measuring track. The longwall face, mined by a longwall shearer, is flat during normal operation and becomes irregular after rock falls. To simulate the mining conditions, the measurements were carried out with the use of an inhomogeneous surface made of coal pieces. The use of coal simulated a material of comparable parameters to the real ones, i.e. the sound absorption coefficient. Both surfaces are shown in Fig. 7. The results are presented in Fig. 10.

The level of signals reflected from an uneven coal surface is significantly lower, which will negatively affect the measuring range of the sensor. The sensor will be attached to the canopy of the shield support in such a place as to be as low as possible exposed to damage from the cutting head. Depending on the design of the shield support, there may be many obstacles between the sensor and the longwall face, mainly structural components of the canopy. 


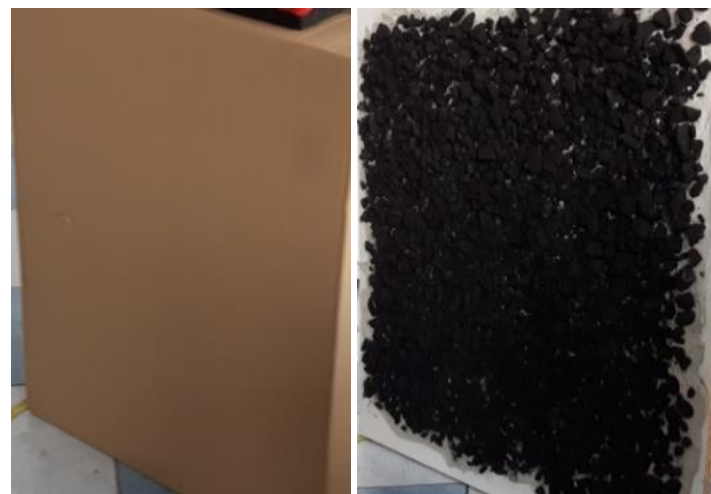

Fig. 7. Flat and uneven coal surface used for testing

In the shield support shown in Fig. 14, for which the sensor is dedicated, the end part of the canopy is pulled out, and at the end of the canopy, there is a longwall face front shield. In such a case, the received signal does not have the form shown in Fig. 3 but can take the form similar to the one shown in Fig. 8.

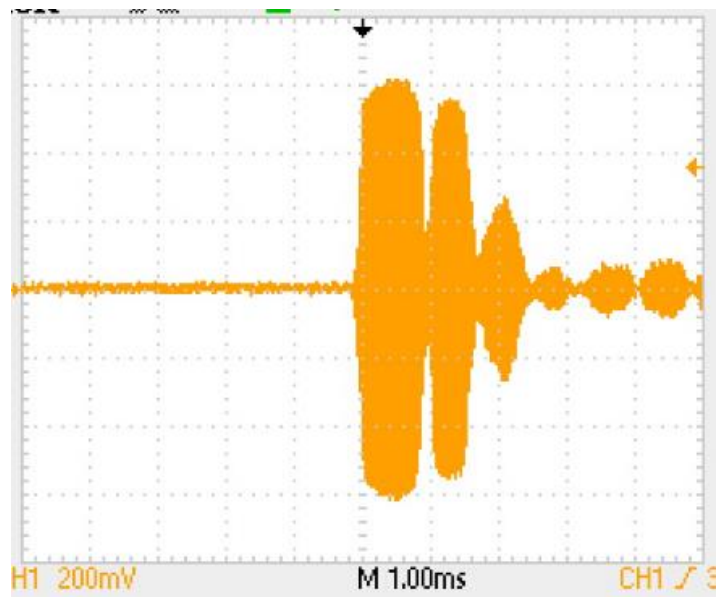

Fig. 8. Signal heavily disturbed

From such a time process, it is difficult to distinguish the proper part representing the echo. In order to minimise the impact of interference from obstacles around the measuring track and at the same time increase the amplitude of the received signal, it was decided to place the transducers in tubes that direct the ultrasonic waves (Fig. 9). The tube in which the transmitter is placed has an end bevelled at $45^{\circ}$ to guide the reflected waves in the chosen direction.

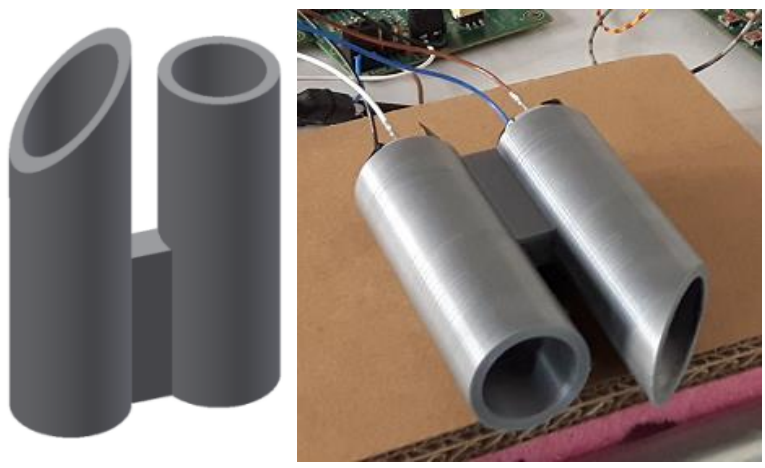

Fig. 9. Ultrasonic tubes 


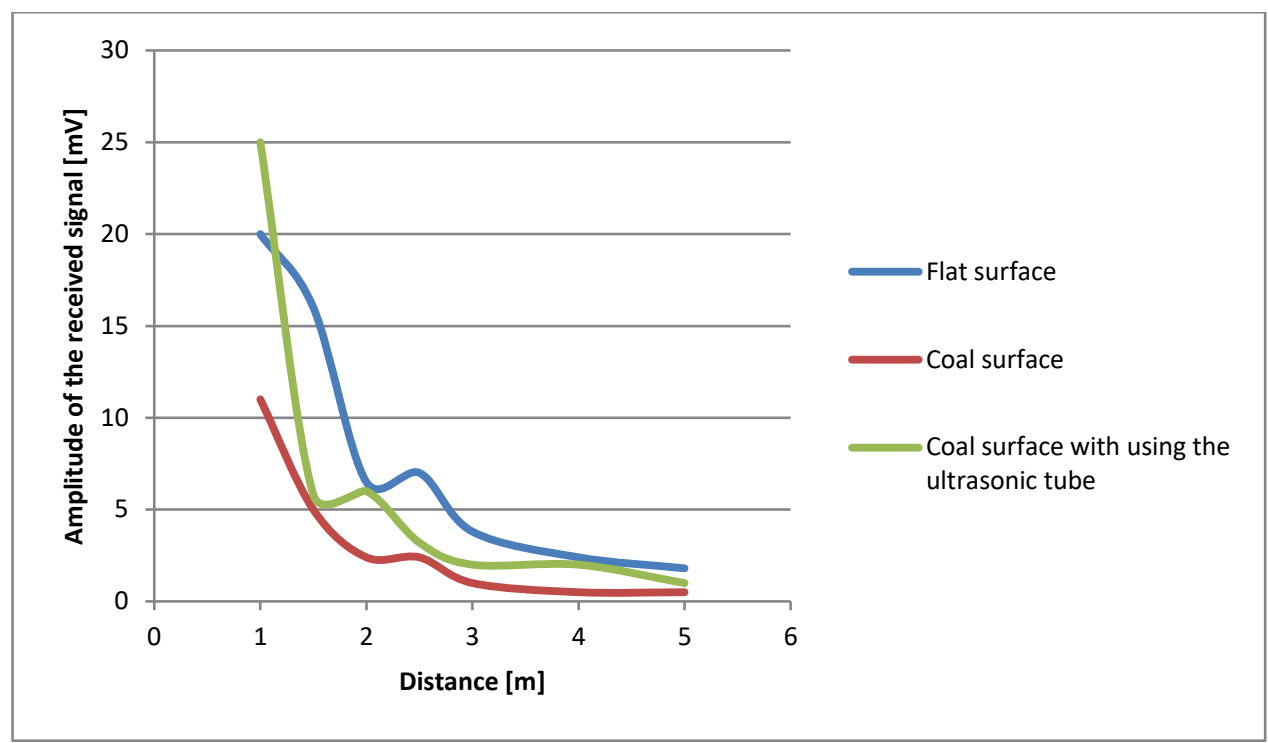

Fig. 10. Signal level reflected from two types of surface: flat and uneven using the $32.8 \mathrm{kHz}$ ultrasonic transducers

Fig. 11 and 12 present the measurements results. The first figure shows a strong, undisturbed echo signal. In this case, the result is easy to interpret.

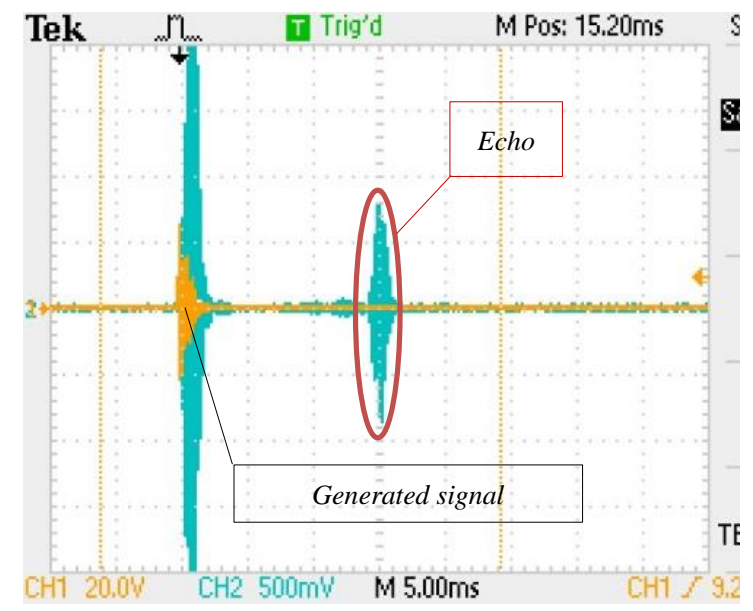

Fig. 11. Strong signal recorded

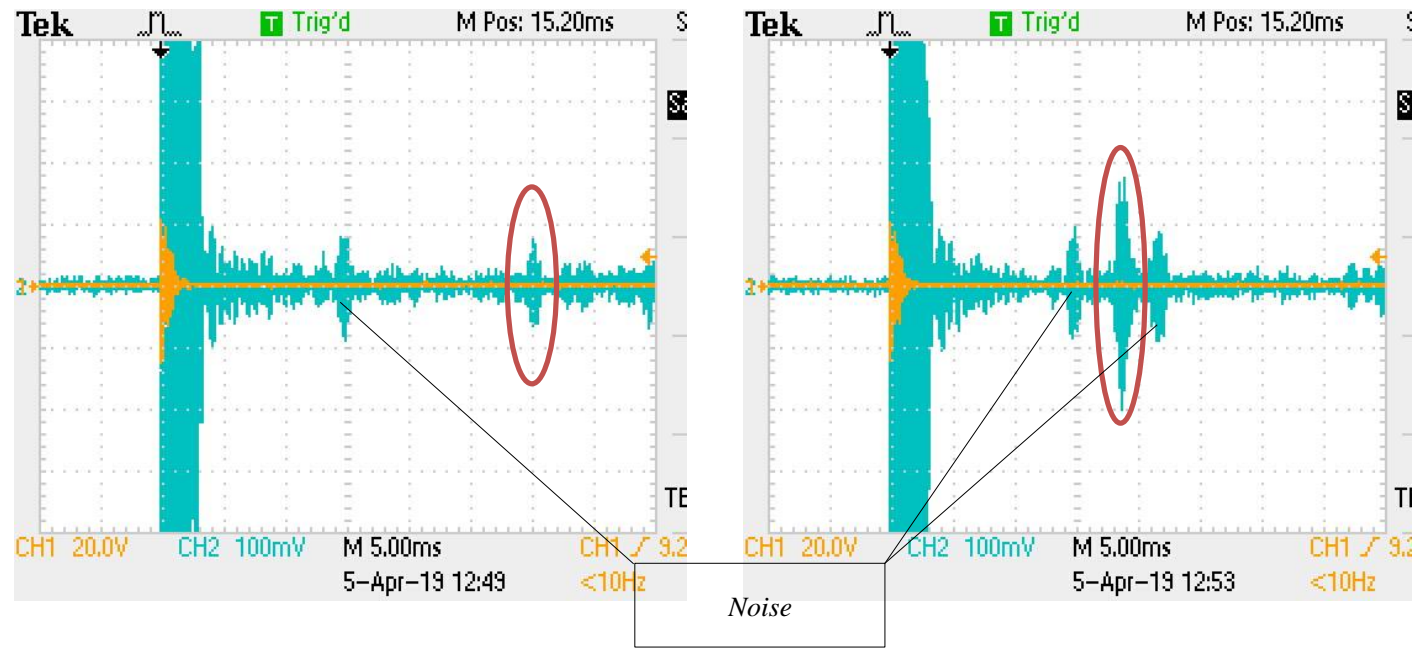

Fig. 12. Weak signal recorded 
In Figure 12, the red marked echo has a comparable amplitude to interference from obstacles located just next to the measuring track. Therefore, the sensor should use proper filtration of received signals with an algorithm searching for the correct echo signal.

The sensor is shown in Figure 13. It was made of stainless steel, which ensures greater resistance to damage, and the shape of the enclosure was adapted to the structure of the shield support. Figure 14 shows the shield support with a marked SSMS-S sensor mounting place. It also shows its model mounted on the canopy. There is only a small free space through which ultrasonic waves can propagate in a longwall face direction because, in front of the sensor, there is a pull-out end part of the canopy and an articulated longwall front shield.

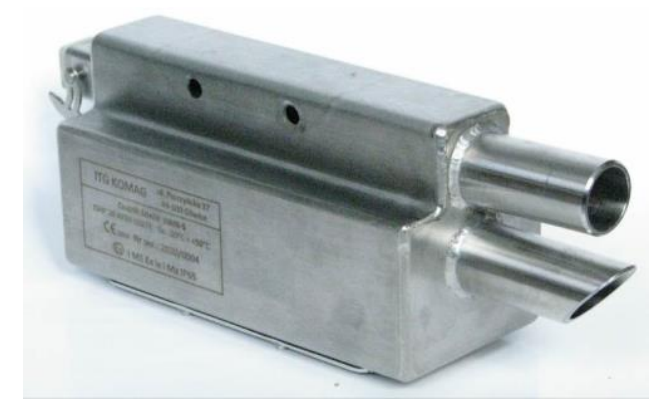

Fig. 13. SSMS-S sensor

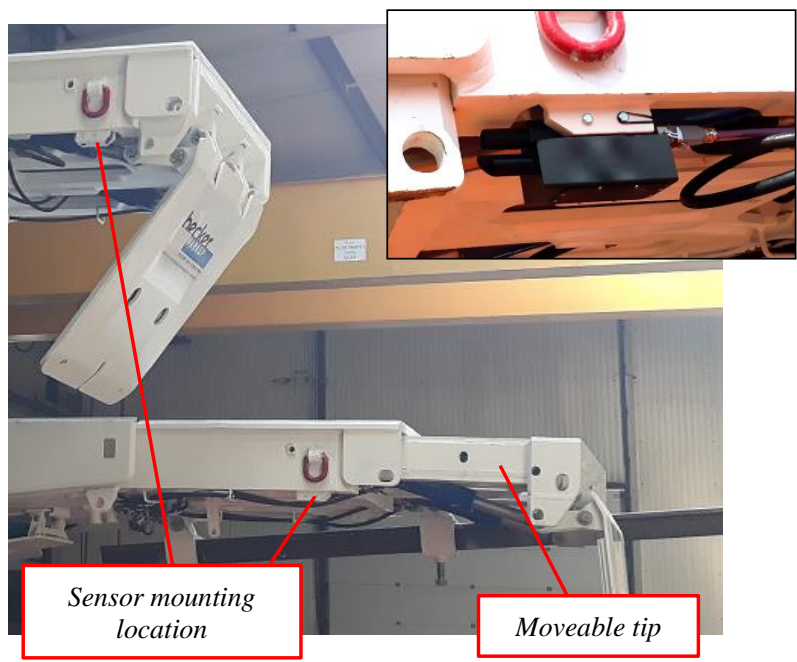

Fig. 14. SSMS-S sensor and its mounting location

Figure 15 shows a block diagram of the part responsible for generating the signal informing about the moment of ultrasonic wave reception. The first element in the presented measurement track is an active bandpass filter. The passband frequency range is adjusted to selected ultrasonic transducers. The second part of the circuit determines the envelope of the received signal. The envelope is given to the comparator, which in the case of signal detection generates a signal which is a source of interruption in the microcontroller.

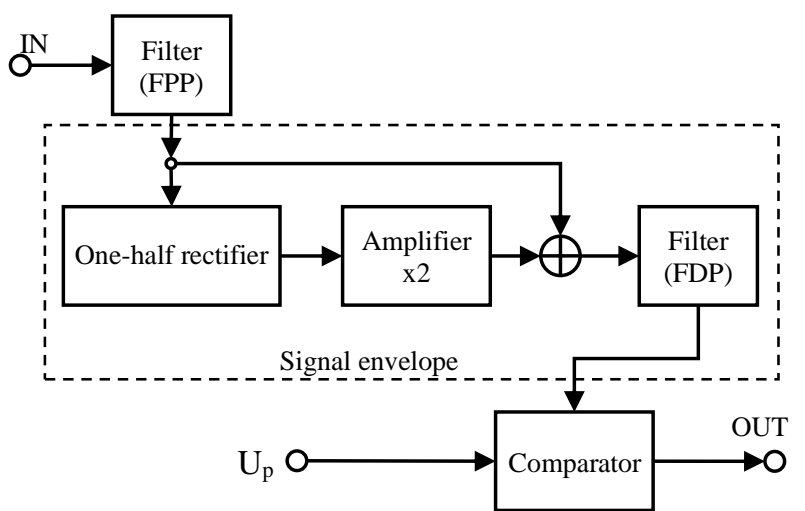

Fig. 15. Block diagram of the SSMS-S sensor electronic - system generating the signal informing about the moment of ultrasonic wave reception 
Figure 16 shows the signal received by the sensor during measurements. The microcontroller first interprets the envelope signal of the received signal marked in purple and the signal indicating the presence of the signal marked in green.
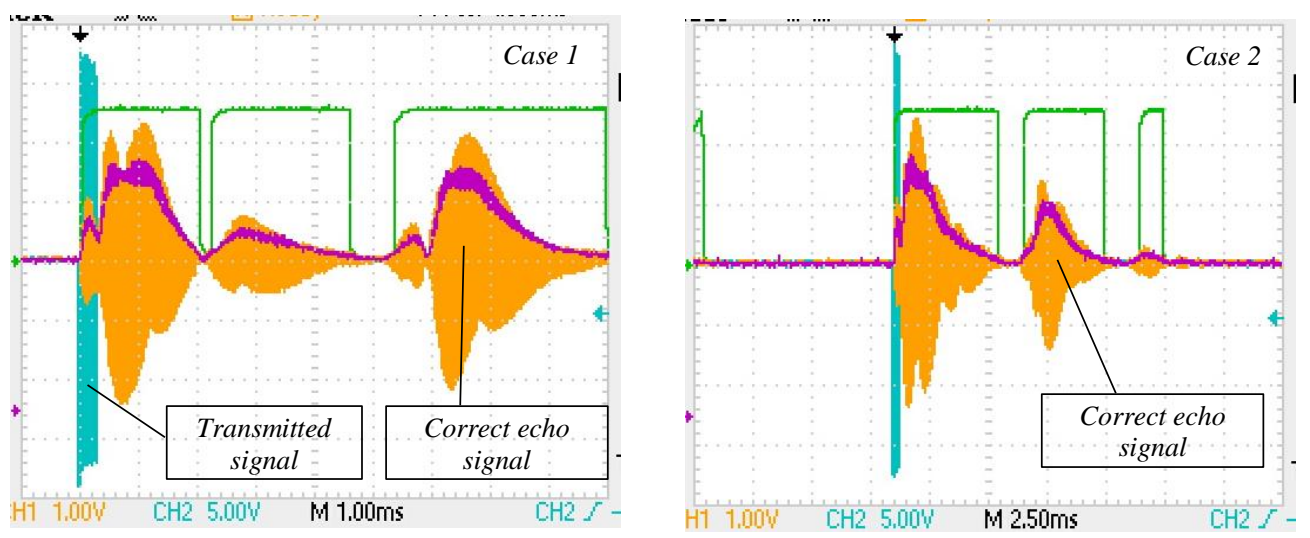

Fig. 16. Signal recorded by the sensor measuring channel

In addition to the correct response, each signal contains additional unresponsive pulses. The first impulse is caused by the transmitter system, whose vibrations are transmitted to the receiving system (Akatov et al., 2019). The next pulses are the expected echo reflected from the longwall face and additional wave reflections from other obstacles (Kuric et al., 2019). Since the structure of the longwall is heterogeneous, the form of the received signal may be different. The microcontroller interprets each received signal pulse whose energy is large enough to trigger the output of the comparator, which is a part of the measuring path (Pástor et al., 2020). The comparator generates a signal marked green. The selected parameters of the recorded signals are interpreted (Sága et al., 2019). These parameters are subjected to digital FIR filtration, according to the following equation (Eq. 6):

$$
y(n)=\frac{1}{N} \sum_{k=0}^{N-1} x(n-k)
$$

To choose the right impulse, representing the echo of the signal reflected from the face of the longwall, a coefficient is defined by the following formula (Eq. 7):

$$
w_{i}=h_{1 i} \cdot w_{a i}+h_{2 i} \cdot w_{t i}+h_{3 i} \cdot w_{e i}
$$

where: $h_{x i}$ - empirically matched weights, $w_{a i}$ - pulse amplitude, $w_{t i}$ - time of pulse maximum, $w_{e i}-$ pulse energy. The coefficient that takes the highest value decides. For its calculation, the following factors are taken into account: the amplitude of the voltage representing a single pulse, propagation time till the moment when the voltage is highest, as well as the energy of the whole pulse (Kuric, 2011). A weight is assigned to each coefficient. Values of weights are selected empirically and depend on the specific location of the sensor and the type of shield support.

\section{Conclusions}

The SSMS-S sensor is used to measure the distance between the shield support canopy and the longwall face and is part of a system that detects and predicts threats related to rock falls. The sensor provides information about the condition of the longwall roof because the empty spaces appearing after the rock falls indicate abnormal behaviour of the roof. Improper support of the roof in the long term may be the reason. Development of a dedicated sensor was necessary due to the unusual location of the sensor, harsh environmental conditions, legal requirements and unusual requirements for its operation, i.e. operation for at least one year on one set of batteries.

Based on the tests, it can be concluded that the chosen measurement method using ultrasonic waves is suitable for the assumed distance of several meters. Due to the presence of obstacles in the measurement path, which are the source of interference, ultrasonic tubes were used to direct the generated waves and a method of recognising the echo signal dedicated to this application was developed.

The sensor and the entire system are currently being tested under real conditions at the mine. 


\section{References}

Akatov, N., Klačková, I., Mingaleva, Z, Galieva, G., Shaidurova, N. (2019). Expert technology for risk management in the implementation of QRM in a high-tech industrial enterprise, Management Systems in Production Engineering, 27, p.p. 250-254.

Andras, A., Andras, I., Tomus, O.-B. (2017). Mathematical models of powered roof support interaction with surrounding rocks. International Multidisciplinary Scientific GeoConference Surveying Geology and Mining Ecology Management, SGEM, 17 (13), pp. 529-536.

Bartoszek S., Kost G., (2018). Method for positioning of a roadheader in a roadway, KOMAG Institute of Mining Technology, Monograph 55, Gliwice (in Polish)

Biryukova, O.V., Koretskaya, I.V. (2020). Selection of Ultrasonic Sensors for Distance Monitoring. Systems of Signal Synchronization, Generating and Processing in Telecommunications, SYNCHROINFO 2020, art. no. 9166089.

Chen, Q.-F., Zheng, W.-S., Niu, W.-J., Liu, J.-G., Zhao, F.-Y. (2017). Deconstruction research to determine the jointed rock mass caving recovery roadway roof risk area. Disaster Advances, 10 (5), pp. 24-35.

Cheng, J., Wan, Z., Peng Syd, S., Zhang, H., Xing, K., Yan, W., Liu, S. (2020). Technology of intelligent sensing of longwall shield supports status and roof strata based on massive shield pressure monitoring data. Meitan Xuebao/Journal of the China Coal Society, 45 (6), pp. 2090-2103.

Frith R. (2013): A holistic examination of the geotechnical design of longwall shields and associated mining risks, 13th Coal Operators' Conference, University of Wollongong, The Australasian Institute of Mining and Metallurgy \& Mine Managers Association of Australia, pp. 38-49

Gudra T., (2005). Właściwości i zastosowanie przetworników ultradźwiękowych do pracy w ośrodkach gazowych, Oficyna Wydawnicza Politechniki Wrocławskiej in Wrocław (in Polish)

Haijun J, Shenggen C, Yun Z, Chen W. (2016). Analytical solutions of hard roof's bending moment, deflection and energy under the front abutment pressure before periodic weighting. International Journal of Mining Science and Technology, 26, 175-181.

Islavath SR, Deb D, Kumar H. (2016). Numerical analysis of a longwall mining cycle and development of a composite longwall index. International Journal of Rock Mechanics and Mining Sciences. Vol. 89, 43-54

Janu, P., Sramek, R. (2020). Intelligent distance measuring module using ultrasonic piezoelectric ceramic transducers. Przegląd Elektrotechniczny, 96 (11), pp. 147-150

Jasiulek D., (2019). Monitoring of the mining powered roof support geometry, Journal of Machine Construction and Maintenance, no. 3, pp. 73-79

Jasiulek, D., Bartoszek, S., Perutka, K., Korshunov, A., Jagoda, J., Plonka, M., (2019). Shield Support Monitoring System - operation during the support setting, Acta Montanistica Slovaca, Vol. 24. Issue: 4/2019, pp. 391401

Jingyi Cheng, Zhijun Wan, and Yinlin Ji, (2018). Shield-Roof Interaction in Longwall Panels: Insights from Field Data and Their Application to Ground Control. Advances in Civil Engineering, vol. 2018, Article ID 3031714, 18 pages. https://doi.org/10.1155/2018/3031714

Kalentev, E., Vaclav, S., Bozek, P., Tarasov, V. and Korshunov, A. (2017). Numerical analysis of the stress-strain state of a rope strand with linear contact under tension and torsion loading conditions. ADVANCES IN SCIENCE AND TECHNOLOGY-RESEARCH JOURNAL, Vol. 11, Issue: 2, p 231-239

Kim, K., Choi, D., Im, S. (2019). The application of ultrasonic waves and envelope energies in a closed chamber based on an air/methane mixture. Ultrasonics, 91, pp. 92-102.

Kuric, I. (2011). New methods and trends in product development and planning. 1st International Conference on Quality and Innovation in Engineering and Management (QIEM). Cluj Napoca, 17.3.-19.3. 2011, p.p. 453456, ISBN:978-973-662-614-2

Kuric, I.; Cisar, M.; Tlach, V.; et al. (2019). Technical Diagnostics at the Department of Automation and Production Systems. Book Series: Advances in Intelligent Systems and Computing, vol. 835, p.p. 474-484.

Langosch U.; Volker S. (2003): 'Improved coal face support by calculation of the required shield support performance'; Glückauf 139 no. 9; paper presented at the 3rd International Symposium on High-performance Coal Faces, Aachen.

Le, T.D. (2021) Analytical Study on the Stability of Longwall Top Coal Caving Face. Lecture Notes in Civil Engineering, 109, pp. 308-319.

Pástor, M.; Živčák, J.; Puškár, M.; Lengvarský, P.; Klačková, I. (2020) Application of Advanced Measuring Methods for Identification of Stresses and Deformations of Automotive Structures, In Journal; Applied Sciences, vol. 10 (21), article number 7510, MDPI, ISSN 2076-3417.

Plets, D., Deprez, W., Trogh, J., Martens, L., Joseph, W. (2019). Joint Received Signal Strength, Angle-of-Arrival, and Time-of-Flight Positioning. 13th European Conference on Antennas and Propagation, EuCAP 2019, Article number 8739265 
Płonka M, Rajwa S. (2018). Difficulties observed in operating powered roof support during work in lower range of its working height. Mining - Informatics, Automation and Electrical Engineering, 4(536), 45-54.

Płonka M., Rajwa S., Lubosik Z. (2017). Assessment of shield support operations based onpressure monitoring and its advance. Przegląd Górniczy, T. 73(4), 25-33.

Prusek S., Płonka M., Walentek A., (2016). Applying the ground reaction curve concept to the assessment of shield support performance in longwall faces, Arabian Journal of Geosciences volume 9, Article number: 167

Prusek S., Masny W. (2015). Analysis of damage to underground workings and their sup-ports caused by dynamic phenomena. Journal of Mining Science, 51(1), 63-72.

Rajwa S. (2016). The influence of bearing capacity of mine floor on the conditions for maintaining the roof in longwalls. Przegląd Górniczy, T.72(10), 44-50.

Rajwa S, Prusek S, Szuścik J, Gąska R. (2017). The extraction of longwall panel located under goafs in the conditions of varying thickness of abandoned coal in the bottom layer. Przegląd Górniczy, T. 73(6), 33-37.

Rajwa, S., Lubosik, Z., Płonka, M. (2019). Safety of longwall mining with caving in the light of data from monitoring systems. IOP Conference Series: Materials Science and Engineering, 679 (1), art. no. 012021.

Rajwa, S. (2020) The influence of the geometrical construction of the powered roof support on the loss of a longwall working stability based on the practical experience. Archives of Mining Sciences, 65 (3), pp. 511529.

Rajwa, S., Janoszek, T., Prusek, S. (2020). Model tests of the effect of active roof support on the working stability of a longwall. Computers and Geotechnics, 118, art. no. 103302.

Sága, M.; Vaško, M.; Handrik, M.; Kopas, P. (2019). Contribution to random vibration numerical simulation and optimisation of nonlinear mechanical systems, Scientific journal of Silesian University of Technology - Series Transport 103, p.p. 143-154.

Slusariuc, R.I., Marcu, M., Stochitoiu, M.D., Niculescu, T., Popescu, F. (2018). Determination and analysis of distance with ultrasound sensor in gas environment International Multidisciplinary Scientific GeoConference Surveying Geology and Mining Ecology Management, SGEM, 18 (4.1), pp. 249-256.

Szurgacz, D., Brodny, J. (2019). Analysis of the influence of dynamic load on the work parameters of a powered roof support's hydraulic leg. Sustainability Volume 11, Issue 9, Article number 25

Szurgacz D., Brodny J., (2020). Adapting the Powered Roof Support to Diverse Mining and Geological Conditions, Energies, 13(2)

Szurgacz, D., Szolc, P., Styrylski, K. (2020). Increasing production efficiency based on active monitoring of bearing capacity of a powered roof support section in a longwall complex. AIP Conference Proceedings Volume 2209, Article number 020002

Verma A.K., Deb D. (2006). Effect of lithological variations of mine roof on chock shield support using numerical modeling technique. Journal of Scientific and Industrial Research 65(9), 702-712.

Wang, J., Ning, J., Jiang, L., Jiang, J-Q., and Bu, T.. (2018). Structural characteristics of strata overlying of a fully mechanised longwall face: a case study. Journal of the Southern African Institute of Mining and Metallurgy, 118(11), 1195-1204. https://dx.doi.org/10.17159/2411-9717/2018/v118n11a10

Wen, Z., Shiyue, W., Wancheng, Z. (2005). The failure and falling of the rock mass in the underground mining. Key Engineering Materials, 297-300 IV, pp. 2586-2591.

Witek, M., Prusek, S. (2016). Numerical calculations of shield support stress based on laboratory test results. Computers and Geotechnics 72, p. 74-88

Xu, Z., Yang, W., You, K., Li, W., Kim, Y.-I. (2017). Vehicle autonomous localisation in local area of coal mine tunnel based on vision sensors and ultrasonic sensors. PLoS ONE, 12 (1), art. no. e0171012.

Zafari, F., Gkelias, A. Leung, K.K. (2019). IEEE Communications Surveys and Tutorials. Volume 21, Issue 3, Article number 8692423, Pages 2568-259

Zhmud, V.A., Kondratiev, N.O., Kuznetsov, K.A., Trubin, V.G., Dimitrov, L.V. (2018). Application of ultrasonic sensor for measuring distances in robotics. Journal of Physics: Conference Series, 1015 (3), art. no. 032189. 